\title{
Gender and Geocultural Diffrences in Children's Appreciation of Art
}

\author{
Lilly Kannampuzha Varuthunny, Sudhakar Venukapalli* \\ Department of Education, The English and Foreign Languages University, Hyderabad, India \\ Email address: \\ lillychacko@gmail.com (L. K. Varuthunny), sudhakarvenu.efluniversity@gmail.com (S. Venukapalli) \\ ${ }^{*}$ Corresponding author
}

\section{To cite this article:}

Lilly Kannampuzha Varuthunny, Sudhakar Venukapalli. Gender and Geocultural Diffrences in Children's Appreciation of Art. American Journal of Art and Design. Vol. 6, No. 2, 2021, pp. 47-54. doi: 10.11648/j.ajad.20210602.12

Received: May 5, 2021; Accepted: May 24, 2021; Published: May 31, 2021

\begin{abstract}
Art has always fascinated humans and the way people experience its beauty is different in different cultures. Children acquire the language of art through a richness of creative visual content. This makes training children to understand and experience art at a young age becoming important. The objective of the present study is to investigate how boys and girls from different geographical backgrounds (cultural values, social practices, life styles, discursive and material expressions, artefacts, human relationships, etc) appreciate art. The quantitative study explores how boys and girls respond to artworks from different artistic genres. Sixty children studying in grade IX participated in the study. The sample included thirty boys and thirty girls from rural and urban backgrounds, and they are in the age group of 13-15 years. The schools are situated in and around Hyderabad city, South India. Children's expressions of art appreciation are elicited by showing images of nine famous artworks from Western, Middle Eastern and Oriental paintings depicting landscapes. The artworks belonged to representational, semi-representational and abstract genres and are shown randomly to children to obtain their responses. The results of the study showed differences in the appreciation of the three genres of artworks by gender, but no statistically significant differences were observed in the appreciation of representational and semi-representational artworks by boys and girls. On the other hand, there exists a statistically significant difference in the appreciation of abstract artworks by boys and girls. The analysis of appreciation of three genres of artworks with respect to geographical background of children shows statistically significant differences among rural and urban children. The findings of this study can be used by teachers and teacher educators in the designing the right kind of learning experiences in schools.
\end{abstract}

Keywords: Art, Artworks, Art Appreciation, Aesthetic Experience, Beauty

\section{Introduction}

Art has always fascinated humans and the way people experience its beauty is different in different cultures. Jacobsen [1] suggested that cultural differences may be one reason why some things are considered beautiful while others not. Research suggests that there exist cultural variations in artistic expressions by Western and East Asian countries [2]. Kardum, Kuscevic, \& Brajcic, [3] in one of their celebrated work says "Knowing, understanding, and using the language of visual arts is a key component of visual literacy, and it functions as a vital factor in understanding the world and culture in the $21^{\text {st }}$ century"

Children acquire the language of art through a richness of creative visual content. This makes training children to understand and experience art at a young age becoming important. Art education inside and outside of school is known to help children develop perception abilities to understand art. To know the language of art, children should continuously observe and experience art. In schools, though children are engaged in some art making, their opportunities to view art are limited. Studies suggested that "if adults can meaningfully engage children in conversation about artworks, they will be equipped with the ability to reflect on their own artworks as well as adult artworks" [4]. In this context Savva \& Trimis [5] says, "In order to develop children's sense of visual art viewing and making, it is important to discern the types, formats, and curriculum that are appropriate for early childhood education".

Why there should be discussion on art objects in 
classrooms? Efland [6] argued that arts are cognitively significant because "they provide encounters that foster the capacity to construct interpretations." According to Eisner [7], the benefits of arts discussion in classrooms include: "the arts teach students to act and judge in the absence of rule, to rely on feel, to pay attention to nuance, to act and appraise the consequences of one's choices, and to revise and then to make other choices".

Our past experiences play an important role in shaping our perception and appreciation of objects. Traditionally, art appreciation focused on the intrinsic values of art and centred on appreciation of artistic elements including composition, form, colour, light and space. Art appreciation includes varied activities including the ways of responding to an artwork, interpreting an artwork, and understanding the artwork that aims at its meaning. It is a mental process that encompasses identifying various forms of perception and presentation portrayed in the artwork. Law [8] argues that all students should be provided opportunities to participate in issues and debates related to art to cultivate an intellectual response to art.

Recent art appreciation theories [9, 10] argue that there exists an interaction between the cognitive and emotional factors influencing aesthetic appreciation. Research proposed that "an art viewer, initially assess the perceptual features of the stimulus during aesthetic perception"[10]. This process occurs very quickly, and these fluent experiences results in positive emotional states [11]. This stage is followed by the understanding of the artwork which includes "explicit processing of stimulus features like content and style of the artwork" [12]. Evaluation of artworks at this stage is affected by the perceivers' thoughts and emotions about the artwork and Schwarz \& Clore [13] argued that "thoughts and feelings influence one another." Thus, "aesthetic experience emerges from a complex interplay of cognitive and emotional processes" [10].

\section{Children's Experiences with Artworks}

Children articulate their wonder and awe while engaging with an artwork and their aesthetic responses are evident through their spontaneity. While encountering an artwork, children come to understand multiple interpretations of familiar themes. Through this process children learn to appreciate artworks and comprehend that "each artwork is a unique expression of the artist" [14]. This implies that children who are exposed to quality art over a period exhibits higher levels of aesthetic appreciation [15]. This helps children to develop perceptual and aesthetic skills [16] and to "develop the seamless synthesis of perceiving, feeling, and thinking, which is an important aim of education and art education in particular [17].

The artworks function as a suitable visual medium for the children to verbally express their thinking $[15,18]$. Children employ their perceptual abilities and conceptual knowledge to respond to the artworks. Research suggests that art is a primary medium of human communication. House \& Rule
[19] suggests that "when children interpret artworks, they develop inventive problem-solving abilities, apply analytic and synthetic forms of reasoning, and learn to exercise judgement." It is found that when children are exposed to visual arts at an early stage, it helps sensory and perceptual development which acts as a foundation for early learning [20, 21].

As a nation we have come to an understanding that opportunity to learn about arts and experiencing it are beneficial for all students. The National Curriculum Framework-2005 [22] states that the arts in India illustrates the "country's secular nature and cultural diversity." Viewing and experiencing art may help children become self-directed learners to enrich the creative and innovative thinking processes that are valued as $21^{\text {st }}$ century skills [23]. It is important that teachers and teacher educators know how children from different backgrounds engage with artworks to design the right kind of learning experiences and curriculum in schools.

\section{The Objectives of the Study}

The objective of the study is to investigate children's expressions of art appreciation with respect to gender. The quantitative study explores how boys and girls from different geographical backgrounds respond to artworks from different artistic genres. Children's expressions of art appreciation are gathered from their descriptions of artworks.

Sixty children studying in grade IX participated in the study. The sample included thirty boys and thirty girls from rural and urban backgrounds, and they are in the age group of 13-15 years. The schools are situated in and around Hyderabad in Telangana state.

The sample has a mean age of 14.2 years and a standard deviation of 0.81 . The mean age for rural and urban children are 14.7 years and 13.6 years respectively with a corresponding standard deviation of 0.58 and 0.56 . On the other hand, the mean age for girls is 14 years with a standard deviation of 0.91 and for boys 14.3 years and the standard deviation is 0.81 . The age range for all children are $13-15$ years.

To avoid the mediated effect of art-related knowledge [24], the researcher selected only art naïve participants. They had not taken part in any systematic art-related education and art training as reported in the Art Expertise Questionnaire. The Art Expertise Questionnaire collected information on the participants' interest in arts, any art education classes attended, and the time spent on arts activities on a weekly basis. The children are initially informed about art appreciation, artworks by various artists that belong to different artistic genres and the procedures involved in the study.

\section{Stimuli Used in the Study}

Children's expressions of art appreciation are measured by showing images of nine famous artworks depicting 
landscapes. Children prefer landscapes as well as those with water or distance [25]. Landscapes depict a scenic view including hills, mountains, river, forests, and the like. The images of artworks shown to children belonged to three artistic genres namely representational, semi-representational and abstract artworks.

The artworks belonged to Western, Middle Eastern and Oriental paintings. The paintings are chosen based on relevant books on art history and intersubjective agreement of art experts. Until mid- $19^{\text {th }}$ century, western paintings were primarily concerned with representational and classical modes of production. Presently western style includes modernism, cubism, surrealism, expressionism, abstract style, and impressionism. The artworks characterise specific artistic periods: Renaissance/Baroque, Impressionism and Abstraction. Middle eastern (West Asia) paintings are dominated by Muslim decorative arts and includes stylized geometric and floral motifs. Oriental paintings or Asian art originated from various Asian cultures and reflect on the society in which it was produced. Oriental art includes Chinese, Japanese, Korean and Indian art along with art from Central and Southeast Asia. Three different types of paintings are included in the study as they portray stylistic characteristics and culture of that region.

The Representational artworks attempt to recreate the landscape in a realistic way. In a semi-representational artwork, the landscape appears realistic from far but when comes close, the brushstrokes seem to be slightly distorted. In abstract artworks, colour, line, and form are distorted and there is no similarity to an actual landscape. No explicit content is evident in abstract art and importance is given to style. According to Brinkmann, Commare, Leder, \& Rosenberg [26], "abstract art represents a universal class of images that could be understood by everyone because they lack semantic content."

Children favour landscapes as well as those with water or distance. Children's preferences are also affected by artistic features such as colours, medium used and design quality.
Artistic style of the painting such as abstract, realistic, older, or modern also has an impact on the art appreciation of children. "The selection of art styles from representative to abstract can help to understand the developmental progression in art appreciation of children" [25].

\section{Methodology}

Nine images of paintings are shown to children using a projector. All the nine artworks belonging to three artistic genres, i.e., representational, semi-representational and abstract artworks selected from Western, Middle Eastern and Oriental collections are shown randomly to children to elicit their responses. Images of artworks are presented in uncompressed jpg file colour format and the dimensions of various images differed. All images were reduced in size to 1024 pixels. Prior to presenting the target image few sample images of artworks are shown to children to help children comprehend the procedure. All images are shown approximately for five to ten minutes to ensure the completion of children's descriptions of the artworks.

To ensure reliability of the study, all test procedures are administered in a similar pattern for all participants to obtain precise and stable results. The conditions of the tests are standardised, the circumstances are made consistent to reduce any external factors. Sample are selected from the same grade and age group to produce valid results of the study.

To measure children's appreciation of artworks, children's expressions of the nine artworks are coded on a continuous scale of 1-10. The data obtained is tested for normality using Shapiro-Wilk test and assumed to be non-normal. Therefore, non-parametric statistical tests are conducted for analysing the data. Statistical tables are generated for children's expressions of art appreciation by genre (representational, semi-representational and abstract). To test gender-wise differences between children's appreciation of representational, semi-representational and abstract artworks, Mann-Whitney U test is used.

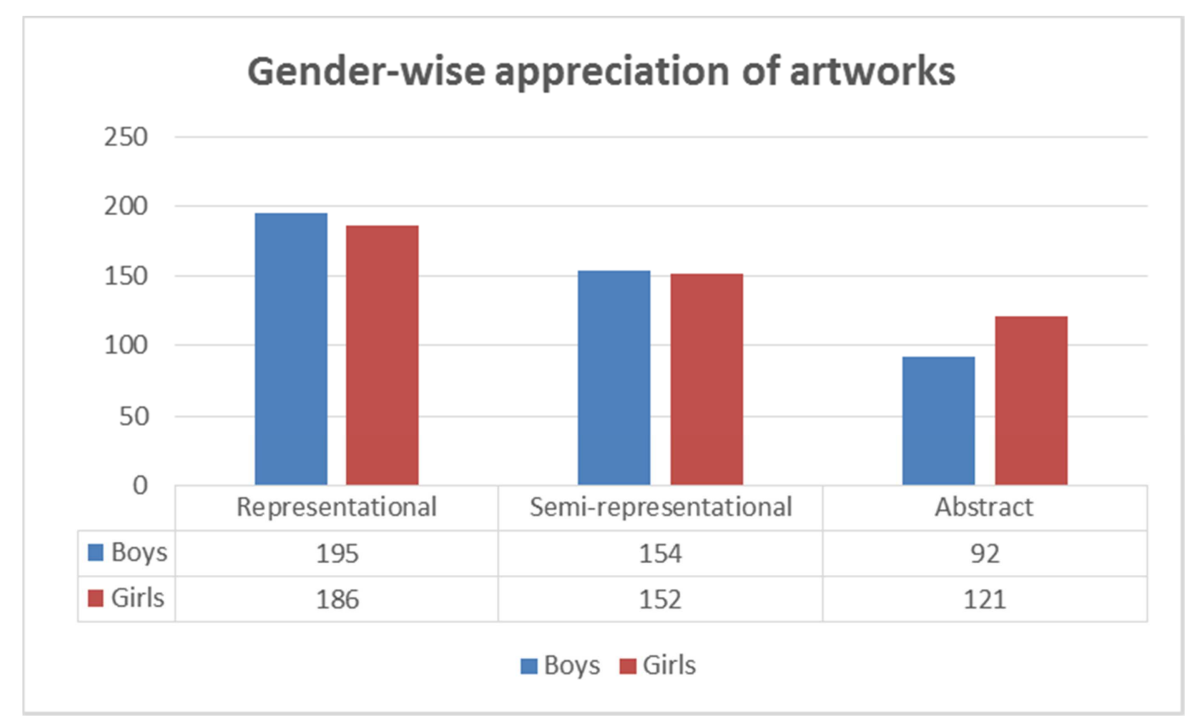

Figure 1. Gender-wise appreciation of artworks. 


\section{Results of the Study}

\subsection{Children's Appreciation of Artworks with Respect to Gender}

Children's appreciation of three genres of artworks are analysed quantitatively with respect to gender. Art appreciation is obtained from their descriptions of artworks. Children's descriptions are scored on a continuous scale of 110 for representational, semi-representational and abstract artworks. The scores are tabulated for the three genres of artworks. The results of the analysis of gender-wise descriptions of artworks are given below.

The analysis of overall appreciation of three genres of artworks with respect to gender shows that the total scores for boys' appreciation of representational, semirepresentational and abstract artworks are 195, 154 and 92, respectively. The total scores for girls' appreciation of representational, semi-representational and abstract artworks are 186, 152 and 121, respectively. To conclude, a difference is evident in the appreciation of artworks by boys and girls.

\subsection{Appreciation of Representational Artworks by Gender}

As discussed above, a difference is noted between the appreciation of representational, semi-representational and abstract artworks by boys and girls. It is therefore required to assess if the differences between the appreciation of representational artworks by boys and girls is statistically significant or not. Hence, the following hypothesis is formulated:

$\mathrm{H}_{1}$ : There is a significant difference between the appreciation of representational artworks by boys and girls.

To test this hypothesis, the above hypothesis is translated into null form.

$\mathrm{H}_{0}$ : There is no significant difference between the appreciation of representational artworks by boys and girls.

The above null hypothesis is tested through Mann Whitney $\mathrm{U}$ test and the results are given below:

Table 1. Mann-Whitney $U$ test results-Appreciation of representational artworks by gender.

\begin{tabular}{lllll}
\hline & Gender & N & Mean Rank & $\begin{array}{l}\text { Sum of } \\
\text { Ranks }\end{array}$ \\
\hline $\begin{array}{l}\text { Representational } \\
\text { artworks }\end{array}$ & Boys & 30 & 29.10 & 873.00 \\
& Girls & 30 & 31.90 & 957.00 \\
\hline
\end{tabular}

\begin{tabular}{ll}
\hline Test Statistics $^{\mathbf{a}}$ & \\
\hline & Representational artworks \\
\hline Mann-Whitney U & 408.000 \\
Wilcoxon W & 873.000 \\
Z & -.656 \\
Asymp. Sig. (2-tailed) & .512 \\
a. Grouping Variable: Gender & \\
\hline
\end{tabular}

From the above table, it is observed that the mean rank for girls is 31.90 and is higher than the mean rank for boys which is 29.10. From the Mann-Whitney $U$ statistical analysis, it is found that $\mathrm{U}$ value is $408, \mathrm{Z}$ score is -0.656 and the $\mathrm{p}$ value is 0.512 . With a $\mathrm{p}$ value $0.512(>0.05)$, the null hypothesis is accepted. Therefore, it is inferred that there does not exist a statistically significant difference in the appreciation of representational artworks by boys and girls $(\mathrm{U}=408, \mathrm{p}=0.512)$.

\subsection{Appreciation of Semi-representational Artworks by Gender}

As shown in figure 1, a difference is noted between the appreciation of semi-representational artworks by boys and girls. It is therefore required to assess if differences between the appreciation of semi-representational artworks by boys and girls is statistically significant or not. Hence, the following hypothesis is formulated:

$\mathrm{H}_{1}$ : There is a significant difference between the appreciation of semi-representational artworks by boys and girls.

To test this hypothesis, the above hypothesis is translated into null form.

$\mathrm{H}_{0}$ : There is no significant difference between the appreciation of semi-representational artworks by boys and girls.

The above null hypothesis is tested through MannWhitney $\mathrm{U}$ test and the results are given below:

Table 2. Mann-Whitney $U$ test results-Appreciation of semi-representational artworks by gender.

\begin{tabular}{|c|c|c|c|c|}
\hline & Gender & $\mathbf{N}$ & Mean Rank & $\begin{array}{l}\text { Sum of } \\
\text { Ranks }\end{array}$ \\
\hline $\begin{array}{l}\text { Semi- } \\
\text { representationa } \\
1 \text { artworks }\end{array}$ & $\begin{array}{l}\text { Boys } \\
\text { Girls } \\
\text { Total }\end{array}$ & $\begin{array}{l}30 \\
30 \\
60 \\
\end{array}$ & $\begin{array}{l}27.97 \\
33.03\end{array}$ & $\begin{array}{l}839.00 \\
991.00\end{array}$ \\
\hline \multicolumn{5}{|l|}{ Test Statistics $^{\mathrm{a}}$} \\
\hline & & \multicolumn{3}{|c|}{ Semi-representational artworks } \\
\hline $\begin{array}{l}\text { Mann-Whitney U } \\
\text { Wilcoxon W } \\
\text { Z } \\
\text { Asymp. Sig. (2-ta } \\
\text { a. Grouping Varia }\end{array}$ & $\begin{array}{l}\text { led) } \\
\text { ole: Gender }\end{array}$ & $\begin{array}{l}374.000 \\
839.000 \\
-1.188 \\
.235\end{array}$ & & \\
\hline
\end{tabular}

From the above table, it is observed the mean rank for girls is 33.03 and is higher than the mean rank for boys which is 27.97. From the Mann-Whitney $U$ statistical analysis, it is found that $\mathrm{U}$ value is $374, \mathrm{Z}$ score is -1.188 and the $\mathrm{p}$ value is 0.235 . With a $p$ value $0.235(>0.05)$, the null hypothesis is accepted. Therefore, it is inferred that there does not exist a statistically significant difference in the appreciation of semirepresentational artworks by boys and girls $(\mathrm{U}=374, \mathrm{p}=$ $0.235)$.

\subsection{Appreciation of Abstract Artworks by Gender}

As presented in figure 1, a difference is noted between the appreciation of abstract artworks by boys and girls. It is therefore required to assess if differences between the appreciation of abstract artworks by boys and girls is 
statistically significant or not. Hence, the following hypothesis is formulated:

$\mathrm{H}_{1}$ : There is a significant difference between the appreciation of abstract artworks by boys and girls.

To test this hypothesis, the above hypothesis is translated into null form.

$\mathrm{H}_{0}$ : There is no significant difference between the appreciation of abstract artworks by boys and girls.

The above null hypothesis is tested through MannWhitney $\mathrm{U}$ test and the results are given below:

Table 3. Mann-Whitney $U$ test results-Appreciation of abstract artworks by gender.

\begin{tabular}{lllll}
\hline & Gender & N & Mean Rank & Sum of Ranks \\
\hline \multirow{2}{*}{ Abstract } & Boys & 30 & 22.77 & 683.00 \\
artworks & Girls & 30 & 38.23 & 1147.00 \\
& Total & 60 & & \\
\hline
\end{tabular}

\begin{tabular}{ll}
\hline Test Statistics $^{\mathbf{a}}$ & \\
\hline & Abstract artworks \\
\hline Mann-Whitney U & 218.000 \\
Wilcoxon W & 683.000 \\
Z & -3.567 \\
Asymp. Sig. (2-tailed) & .000 \\
a. Grouping Variable: Gender & \\
\hline
\end{tabular}

From the above table, it is found that the mean rank for girls is 38.23 and is higher than the mean rank for boys which is 22.77. From the Mann-Whitney $U$ statistical analysis, it is found that $\mathrm{U}$ value is $218, \mathrm{Z}$ score is -3.567 and the $\mathrm{p}$ value is 0.000 . With a $\mathrm{p}$ value $0.000(<0.05)$, the null hypothesis stands rejected. Therefore, it is inferred that there exists a statistically significant difference in the appreciation of abstract artworks by boys and girls $(U=218$, $\mathrm{p}=0.000)$.

\subsection{Appreciation of Artworks with Respect to Geographical Background of Children}

Appreciation of three genres of artworks are analysed quantitatively with respect to geographical background of children. The results of analysis of appreciation of artworks with respect to geographical background of children are given below.

The analysis of overall appreciation of three genres of artworks with respect to geographical background of children shows that the total scores for appreciation of representational, semi-representational and abstract artworks by rural children are 179, 144 and 94, respectively. The total scores for appreciation of representational, semi-representational and abstract artworks by urban children are 202, 162 and 119, respectively. The results show a difference in the appreciation of artworks among rural and urban children.

\subsection{Appreciation of Representational Artworks by Rural and Urban Children}

As presented above, a difference is noted in the appreciation of representational artworks by rural and urban children. It is therefore required to assess if the differences between the appreciation of representational artworks by rural and urban children is statistically significant or not. Hence, the following hypothesis is formulated:

$\mathrm{H}_{1}$ : There is a significant difference between the appreciation of representational artworks by rural and urban children.

To test this hypothesis, the above hypothesis is translated into null form.

$\mathrm{H}_{0}$ : There is no significant difference between the appreciation of representational artworks by rural and urban children.

The above null hypothesis is tested through MannWhitney $U$ test and the results are given below:

Table 4. Mann-Whitney $U$ test results-Appreciation of representational artworks by rural and urban children.

\begin{tabular}{lllll}
\hline & Background & N & Mean Rank & Sum of Ranks \\
\hline \multirow{2}{*}{ Representationa } & Rural & 30 & 17.72 & 531.50 \\
1 artworks & Urban & 30 & 43.28 & 1298.50 \\
& Total & 60 & & \\
\hline \multicolumn{5}{l}{ Test Statistics } \\
& & & \\
\hline \multicolumn{4}{l}{ Mann-Whitney U } & Representational artworks \\
Wilcoxon W & & 66.500 & \\
Z & 531.500 & \\
Asymp. Sig. (2-tailed) & -5.992 & \\
Grouping Variable: Background & & & \\
\hline
\end{tabular}

From the above table, it is found that the mean rank for urban children is 43.28 and is higher than the mean rank for rural children which is 17.72 . From the Mann-Whitney U statistical analysis, it is observed that the $\mathrm{U}$ value is $66.500, \mathrm{Z}$ score is -5.992 and the $p$ value is 0.000 . Since $p$ value is 0.000 , the null hypothesis stands rejected. Therefore, it is inferred that there exists a statistically significant difference in the appreciation of representational artworks by rural and urban children $(U=66.500, p=0.000)$.

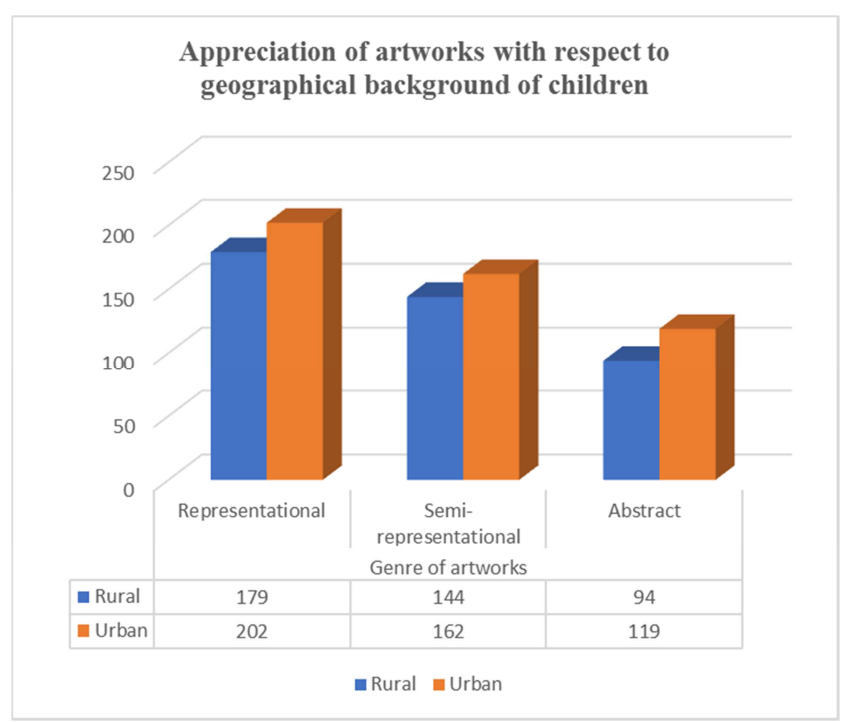

Figure 2. Appreciation of artworks with respect to geographical background of children. 


\subsection{Appreciation of Semi-representational Artworks by Rural and Urban Children}

The figure 2 presented above shows a difference in the appreciation of semi-representational artworks by rural and urban children. It is therefore required to assess if the differences between the appreciation of semi-representational artworks by rural and urban children is statistically significant or not. Hence, the following hypothesis is formulated:

$\mathrm{H}_{1}$ : There is a significant difference between the appreciation of semi-representational artworks by rural and urban children.

To test this hypothesis, the above hypothesis is translated into null form.

$\mathrm{H}_{0}$ : There is no significant difference between the appreciation of semi-representational artworks by rural and urban children.

The above null hypothesis is tested through MannWhitney U test and the results are shown below:

Table 5. Mann-Whitney $U$ test results-Appreciation of semi-representational artworks by rural and urban children.

\begin{tabular}{lllll}
\hline & $\begin{array}{l}\text { Backgrou } \\
\text { nd }\end{array}$ & N & Mean Rank & $\begin{array}{l}\text { Sum of } \\
\text { Ranks }\end{array}$ \\
\hline Semi- & Rural & 30 & 20.02 & 600.50 \\
representational & Urban & 30 & 40.98 & 1229.50 \\
artworks & Total & 60 & & \\
\hline
\end{tabular}

\begin{tabular}{ll}
\hline Test Statistics $^{\mathbf{a}}$ & \\
\hline & Semi-representational artworks \\
\hline Mann-Whitney U & 135.500 \\
Wilcoxon W & 600.500 \\
Z & -4.917 \\
Asymp. Sig. (2-tailed) & .000 \\
a. Grouping Variable: Background & \\
\hline
\end{tabular}

From the above table, it is observed that the mean rank for urban children is 40.98 and is higher than the mean rank for rural children which is 20.02. From the Mann-Whitney U statistical analysis, it is found that the $\mathrm{U}$ value is $135.500, \mathrm{Z}$ score is -4.917 and the $p$ value is 0.000 . Since $p$ value is 0.000 , the null hypothesis stands rejected. Therefore, it is inferred that there exists a statistically significant difference in the appreciation of semi-representational artworks by rural and urban children $(\mathrm{U}=135.500, \mathrm{p}=0.000)$.

\subsection{Appreciation of Abstract Artworks by Rural and Urban Children}

In the figure 2 presented above, a difference is noted between the appreciation of abstract artworks by rural and urban children. It is therefore required to assess if the differences between the appreciation of abstract artworks by rural and urban children is statistically significant or not. Hence, the following hypothesis is formulated:

$\mathrm{H}_{1}$ : There is a significant difference between the appreciation of abstract artworks by rural and urban children.

To test this hypothesis, the above hypothesis is translated into null form.
$\mathrm{H}_{0}$ : There is no significant difference between the appreciation of abstract artworks by rural and urban children.

The above null hypothesis is tested through MannWhitney $\mathrm{U}$ test and the results are presented below:

Table 6. Mann-Whitney $U$ test results-Appreciation of abstract artworks by rural and urban children.

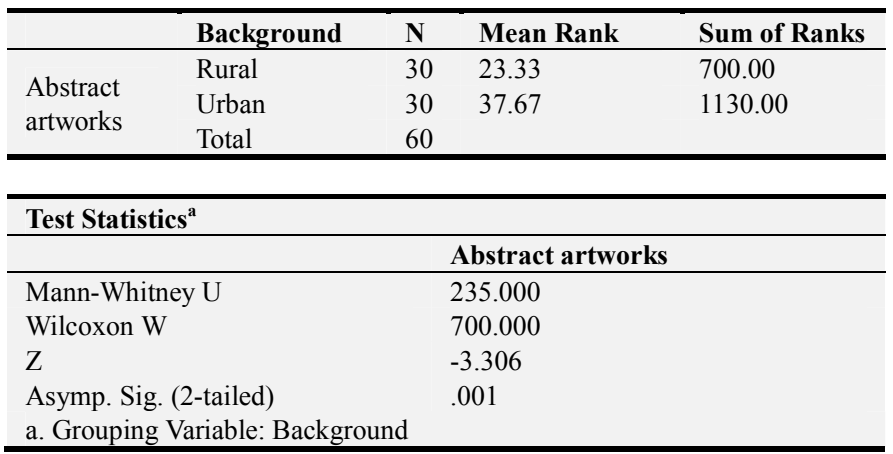

From the above table, it is observed that the mean rank for urban children is 37.67 and is higher than the mean rank for rural children which is 23.33. From the Mann-Whitney U statistical analysis, it is found that the $\mathrm{U}$ value is $235, \mathrm{Z}$ score is -3.306 and the $p$ value is 0.001 . Since $p$ value is 0.001 , the null hypothesis stands rejected. Therefore, it is inferred that there exists a statistically significant difference in the appreciation of abstract artworks by rural and urban children $(\mathrm{U}=235, \mathrm{p}=0.001)$.

\section{Findings and Discussion}

The results of the study support the past findings that children's appreciation of artworks varies based on the genre of painting. The more realistic the artwork, the more children focus on what they see in the artwork and understand the artwork. Children find it difficult to understand and explain abstract artworks. This confirms the findings by Leder \& Nadal [27] that aesthetic appreciation of artworks depends strongly on aspects of cognitive mastering. This results also corroborates Leder et. al.'s [10] hypothesis that comprehension of an artwork is based on content representation in the artwork and Representative classical artworks were understood better by viewers [28]. The results also show children's capability to apply prior knowledge to novel situations to interpret artworks. It was evident in their references made to Biblical stories while describing the artworks.

Though differences were found in the appreciation of the three genres of artworks by gender, there does not exist a statistically significant difference in the appreciation of representational and semi-representational artworks by boys and girls. The results are also in agreement with the previous findings that the influence of gender on art appreciation is minimal. On the other hand, the scores of expressions of art appreciation of abstract artworks by girls are higher than boys and there exists a statistically significant difference in the appreciation of abstract artworks by boys and girls. This result is in conformity with the finding that "women showed 
preference to abstract art more than men" [29] but also contradicts the view by Feist \& Brady [30] that gender has no significant effect on preference ratings for abstract art.

The analysis of appreciation of three genres of artworks with respect to geographical background of children shows that the total scores for appreciation of representational, semi-representational and abstract artworks by urban children are higher than rural children. The results of the statistical analysis show a statistically significant difference in the appreciation of representational, semi-representational and abstract artworks by rural and urban children.

This confirms Parsons' [31] proposition that "the individual's development in art is influenced by cultural, educational and social aspects of experience." Though Parsons proposes a universal aesthetic development theory, he agrees with "the possibility of cultural differences in art appreciation" [31]. Urban children with more opportunities to visit museums and art galleries are familiar with artworks compared to rural children. This result validates the findings by Kardun, Kuscevic, \& Brajcic [3] that formal art education plays an important role in children's art preferences.

It is evident from the 'Art Expertise Questionnaire' that though none of the children who participated in the study had formal art education, few urban children had visited museums and art galleries. The percentage of children who engage with arts activities are also higher among urban children. It is assumed that urban children are more exposed to visual images, arts and artists compared to children living in rural areas. Further, visual experiences are contextual and are bound by social and cultural factors [8]. This might also lead to the significant differences in art appreciation between rural and urban children.

\section{Conclusion}

The present study investigated how boys and girls from rural and urban areas appreciate art by viewing artworks of varied artistic genres. The expressions of art appreciation provided by children reveals that children use descriptive language to identify and narrate paintings and they make logical and personal connections. They make claims depending on their memory and associations based on past experiences. Children articulated, explained, and elaborated on their observations of the artworks. Art appreciation augments children's ability to make opinions and articulate their thoughts and feelings. The findings of this study can be used by teachers and teacher educators in the development of art education curricula. Appreciating artworks require certain skills for comprehending and interpreting the content. Teaching children the required skills for engaging with artworks will help them understand themselves, others, history, and culture. Providing opportunities for children to experiencing artworks may help children develop meaning in life and facilitates positive social change. In the present era of technology, teachers may use digitized collections of artworks to provide access to art and to enhance student engagement with art.

\section{Appendix}

List of paintings used in the study

Pastoral Landscape, Asher Brown Durand, 1861, Hudson

River School.

Water lilies, Claude Monet, 1917, Impressionism.

Landscapes with Red spots no. 2, Wassily Kandinsky, 1913, Abstraction.

An Arab encampment at Sunset, Herman David Salomon Corrodi.

Middle eastern city, unknown, Early $20^{\text {th }}$ century.

Abstract landscape, Shafic Abboud, 1959.

The Watercolour Log, Milind Mulick, contemporary.

Dancing and Singing (Peasants Returning from Work), Ma Yuan, $13^{\text {th }}$ century.

The First Light, Chu Teh Chun, 1987.

\section{References}

[1] Jacobsen, T. (2010). Beauty and the brain: culture, history and individual differences in aesthetic appreciation. Journal of Anatomy, 216, 184-191. doi: 10.1111/j.14697580.2009.01164.x.

[2] Bao, Y., Yang T, Lin X, Fang Y, Wang Y, Pöppel E \& Lei, Q. (2016). Aesthetic preferences for eastern and western traditional visual art: Identity matters. Frontiers in Psychology, 7 (2143). doi: 10.3389/fpsyg.2016.01596.

[3] Kardum, G., Kuscevic, D., \& Brajcic, M. (2017). The Impacts of Different Sorts of Arts Education on Pupils' Preference for $20^{\text {th }}$ - century Art Movements. Creative Commons. doi: 10.20944/preprints201712. 0144.v1.

[4] Anderson, D., Piscitelli, B., Weir, K., Everett, M. \& Tayler, C. (2002). Children's museum experiences: Identifying powerful mediators of learning. Curator, 45, 213-231.Retrieved from $\mathrm{http}: / /$ www.magsq.com.au/dbase upl/curator andersonetal\% 20copy.pdf.

[5] Savva, A. \& Trimis, E. (2005). Responses of young children to contemporary art exhibits: The role of artistic experiences. International Journal of Education and the Arts, 6 (13). Retrieved from http://ijea.asu.edu/v6n13/

[6] Efland, A. D. (2002). Art and cognition: Integrating the visual arts in the curriculum. New York, NY: Teachers College Press.

[7] Eisner, E. W. (Ed.). (2005). Reimagining schools: the selected works of Elliot W. Eisner. New York, NY: Routledge. https://ifarus.com/imagining-schools-the- elliot-eisner.

[8] Law, S. S. M. (2010). An Interdisciplinary Approach to Art Appreciation. New Horizons in Education, 58 (2). Retrieved from https://files.eric.ed.gov/fulltext/EJ966652.pdf.

[9] Chatterjee, A. (2003). Prospects for a cognitive neuroscience of a visual aesthetics. Bulletin of Psychology and the Arts, 4, 55-60. doi: 10.1037/e514602010-003.

[10] Leder, H., Belke, B., Oeberst, A., \& Augustin, D. (2004). A model of aesthetic appreciation and aesthetic judgments. British Journal of Psychology, 95, 489-508. doi: 10.1348/0007126042369811. 
[11] Reber, R., Schwarz, N., \& Winkielman, P. (2004). Processing fluency and aesthetic pleasure: Is beauty in the perceiver's processing experience? Personality and Social Psychology Review, 8 (4): 364-82. doi: 10.1207/s15327957pspr0804_3.

[12] Leder, H., Gerger, G., Brieber, D., \& Schwarz, N. (2014). What makes an art expert? Emotion and evaluation in art appreciation. Cognition and Emotion, 28 (6), 1137-1147. doi: 10.1080/02699931.2013.8701323.

[13] Schwarz, N. \& Clore, G. L. (2007). Feelings and phenomenal experiences. In E. T. Higgins \& A. Kruglanski (Eds.), Social psychology. Handbook of basic principle.

[14] Eckhoff, A. (2010). Using games to explore visual art with young children. Young Children, 65 (1): 18-22. Retrieved from https://www.researchgate.net/publication/290551309.

[15] Housen, A. (2002). Aesthetic thought, critical thinking and transfer. Art and Learning Research Journal, 18, 99-132. Retrieved

from https://pdfs.semanticscholar.org/f92a/f0a61718efaca853d456c 1 edec6817dfee31.pdf? ga $=2.174320491 .838978140 .1577727$ 629-127502483.1577727629.

[16] Zakaras, L. \& Lowell, J.F. (2008). Cultivating demand for the arts: Arts learning, arts engagement, and state arts policy. Rand Corporation. Retrieved from https://www.rand.org/content/dam/rand/pubs/monographs/200 8/RAND_MG640.pdf.

[17] Wright, S. (2003). The arts, young children, and learning. Boston: Allyn and Bacon. Retrieved from https://books.google.co.in/books/about/The_Arts_Young_Chil dren_and_Learning.html?id $=00 \mathrm{ydAAAAMAAJ} \&$ redir_esc $=\mathrm{y}$.

[18] Perkins, D. (2003). Making thinking visible. Harvard Project Zero. Retrieved from http://www.pz.harvard.edu/sites/default/files/MakingThinking Visible_DP.pdf.

[19] House, C. A. \& Rule, A. C. (2005). Preschoolers' ideas of what makes a picture book illustration beautiful. Early Childhood Education Journal, 32 (5): 283-290. doi: 10.1007/s10643-004-1022-7.

[20] Dunn, J. \& Wright, S. (2014). Signs, meaning, and embodiment: Learning and pedagogy, Rouledge International Handbook of the Arts and Education, Routledge.

[21] Rudolf, S. \& Wright, S. (2015). Drawing out the value of the visual: children and young people theorizing time through art and narrative. Journal of Curriculum Studies, 47 (4), 486-507.
Retrieved

from https://doi.org/10.1080/00220272.2015.1006685.

[22] National Curriculum Framework 2005. Retrieved from https://ncert.nic.in/pdf/nc-framework/nf2005-english.pdf.

[23] Bellanca, J. A., \& Brandt, R.S. (2010). $21^{\text {st }}$ Century skills: Rethinking how students learn. Solution Tree Press. Retrieved from http://soltreemrls3.s3-website-uswest2.amazonaws.com/solutiontree.com/media/pdf/study_gui des/21st_Century_Skills_Study_Guide.pdf.

[24] Leder, H., Carbon, C. C., \& Ripsas, A. L. (2006). Entitling art: influence of title information on understanding and appreciation of paintings. Acta Psychologica, 121, 176-198. doi: 10.1016/j.actpsy.2005.08.005.

[25] Gardner, H., Winner, E., \& Kirchner, M. (1975). Children's conceptions of the Arts. Journal of Aesthetic Education, 9 (3), 60-77. Retrieved from http://links.jstor.org/sici?sici $=00218510 \% 28197507 \% 299 \% 3$ A3\%3C60\%3ACCOTA\%3E2.0.CO\%3B2-F.

[26] Brinkmann, H., Commare, L., Leder, H., \& Rosenberg, R. (2014). Abstract art as a universal language? Leonardo, 47 (3): 256-257. doi: 10.1162/LEON_a_00767.

[27] Leder, H. \& Nadal, M. (2014). Ten years of a model of aesthetic appreciation and aesthetic judgments: The aesthetic episode-Developments and challenges in empirical aesthetics. British Journal of Psychology, 105 (4), 443-464. doi: 10.1111/bjop.12084.

[28] Leder, H., Gerger, G., Dressler, S., \& Schabmann, A. (2012). How art is appreciated. Psychology of Aesthetics, Creativity, and the Arts, 6 (1): 2-10. doi: 10.1037/a0026396.

[29] Furnham, A. \& Walker, J. (2001). The influence of personality traits, previous experience of art, and demographic variables on artistic preference. Personality and Individual Differences, 31, 997-1017. doi: 10.1016/S0191-8869(00)00202-6.

[30] Feist, G. J. \& Brady, T. R. (2004). Openness to experience, non-conformity, and the preference for abstract art. Empirical Studies of the Arts, 22 (1): 77-89. doi: 10.2190/Y7CA-TBY6V7LR-76GK.

[31] Parsons, M. J. (1994). Can children do aesthetics? a developmental account. Journal of Aesthetic Education, 28, 33-45. Retrieved from http://www.jstor.org/stable/3333399. 